\title{
Los datos: la cancha donde se juega la democracia
}

Data: the field where democracy is played

Dados: o campo onde se disputa a democracia

Omar RINCÓN

Chasqui. Revista Latinoamericana de Comunicación

N. ${ }^{o}$ 131, abril-julio 2016 (Sección Tribuna, pp. 21-35)

ISSN 1390-1079 / e-ISSN 1390-924X

Ecuador: CIESPAL 


\title{
Resumen
}

La guerra de los datos existe. La guerra, por ahora, la va ganando el capital, las empresas y los gobiernos. Jobs-Zuckerberg-Page-Bezos-EE.UU. y todos los gobiernos están cerca del control total de los datos sobre los sujetos y la sociedad. Nos persiguen y encuentran gracias a nuestras intimidades conectadas. Lo peor, parecemos felices entregados a la vigilancia y el control. En este contexto, los datos son la cancha donde se está jugando la democracia. En este texto-ensayo se pasa del optimismo tecnológico (el big data es solo una tecnología y una maravilla que lo puede todo), a la ironía de la tecnología como dispositivo de poder y al cinismo del big data como ideología.

Palabras clave: Big Data; Internet de las cosas; Facebook; Twitter; Amazon; control; vigilancia; libertad; remix.

\begin{abstract}
The War of the data exists. The war, meanwhile, is overcome by the capital, companies and governments. Jobs-Zuckerberg-Page-Bezos-USA and all governments are near total control of data on individuals and society. They chase and find us thanks to our own connected intimacies. The worst thing is we seem happy in hands of surveillance and control. In this context, the data are the field where democracy is played. This text-essay goes from the technological optimism (the big data is only a technology and a wonder that conquers all), to the irony of technology as a power device and, finally, the cynicism of big data as an ideology.
\end{abstract}

Keywords: Big data; Internet of things; Facebook; Twitter; Amazon; control; surveillance; freedom; remix.

\section{Resumo}

A guerra dos dados existe. E, quem vai ganhando tal guerra é o capital, as empresas e os governos. Jobs-Zuckerberg-Page-Bezos-Estados-Unidos e demais governos têm se aproximado do controle total de dados sobre sujeitos e sociedade. Perseguem-nos e nos encontram graças às nossas intimidades conectadas. E o pior é que parecemos felizmente entregues à vigilância e ao controle. Neste contexto, os dados são o campo onde se disputa a democracia. Neste texto-ensaio propomos uma passagem do otimismo tecnológico (o big data é só uma tecnologia e uma maravilha que pode tudo) à ironia da tecnologia como dispositivo de poder e ao cinismo do big data como ideologia.

Palavras-chaves: Big Data; Internet das coisas; Facebook; Twitter; Amazon; controle; vigilância, liberdade, remix. 


\section{Introducción}

Los héroes digitales varían desde Steve Jobs (Apple), Mark Zuckerberg (Facebook), Larry Page y Sergey Brin (Google) y Jeff Bezos (Amazon) a Richard Stallman (software libre), Julian Assange (Wikileaks), Edward Snowden (el informante) y Hervé Falciani (filtración de datos del banco HSBC en Ginebra). Los héroes, como siempre, dependen del lugar de enunciación política. Los que ponen el capital por encima de todo equiparan libertad de información a libertad de empresa, creen que la extimidad es la fama digital y buscan hacer negocio con las intimidades y los datos de la gente, adoran y celebran a Jobs-Zuckerberg-PageBezos; los que creen en la libertad, lo comunitario, el derecho a la comunicación y la protección de la intimidad siguen a Stallman-Assange-Snowden-Falciani.

La guerra de los datos existe. Somos los homo data: los datos que existimos. La guerra, por ahora, la van ganando el capital, las empresas y los gobiernos: les pertenecemos. Jobs-Zuckerberg-Page-Bezos-EE.UU. y todos los gobiernos (de izquierda y derecha) están cerca del control total de los datos, de los sujetos, de los ciudadanos (¡tal vez los únicos libres sean los desconectados!). Ellos nos buscan y nos encuentran: nosotros por soledad, aburrimiento y superego ponemos nuestras intimidades en público; por consumismo, para obtener rebajas, promociones y privilegios, damos gratis nuestros datos; por farándula y buscar esa celebrity prometida queremos ser adorados por clics y "me gusta”. Y, mientras en los gobiernos todo es oscuro y autoritario, en el mercado celebramos este control como lo más cool, la tendencia para estar en época. En los gobiernos, el control es demoníaco; en el mercado tech, la moda y los proyectos de control de datos tienen el rostro del internet gratis y los mundos libres. Google (Project Loon), Facebook (Internet.org) y Media Development Investment Fund (Outernet) son publicitados como "la revolución", porque no habrá que pagar, bastará con un celular y todo el flujo de información (y entretenimiento) en internet será de uno. Seremos felices porque en esta revolución solo basta con tener un teléfono celular para ser libre (y estar entretenido). Solo que hay un costo: nuestros datos dejan de ser nuestros, les pertenecemos a ellos.

En nombre de lo colectivo y lo libertario luchan Stallman con su idea del "software libre", para que todos compartamos los hallazgos informáticos y los llevemos a usos más solidarios y comunitarios sin pasar por el capital; el copyleft, para luchar contra los derechos de propiedad que quieren imponer los mercantiles; Assange con sus filtraciones de información sobre cómo la guerra es un negocio y la diplomacia un nido de ratas; y los menos espectaculares pero que llevaron el asunto de los datos al campo de una guerra por la democracia: Snowden y Falciani, quienes han puesto a gobiernos de derecha y de izquierda de acuerdo en el asunto de controlar los datos y perseguir intimidades. La guerra la vamos perdiendo los ciudadanos porque Assange está preso, Snowden está preso, Stallman está silenciado mediáticamente, Falciani vive como un nómada perseguido por el capital. Por ahora, los empresarios y gobiernos van ganando; 
los ciudadanos tenemos poca conciencia y pareciese que no nos importara. Por eso, afirmo que los datos son la cancha donde se está jugando la democracia (y no tenemos conciencia de esto).

La espectacularidad de Assange recayó en demostrar que importan más los chismes de diplomáticos que las guerras mundiales, la importancia enorme de Snowden está en que puso en evidencia la vigilancia masiva que se lleva a cabo sobre los ciudadanos, el valor de Faciani es que documentó cómo los capitales valen más que las personas. Capital y política que nacen de un amantazgo entre gobiernos y empresas y donde la clave del amor son los datos: los gobiernos crean leyes y vigilan en nombre de la seguridad nacional y las empresas vigilan y controlan en nombre de las acciones en bolsa; una estrategia de negocio que saca dinero y poder de los datos (big data); una sociedad que, como dice Jorge Carrión (2015), pasó del Gran Hermano a la Big Data como violación de la privacidad, la intimidad y el anonimato. Frente a esta dura realidad, solo nos queda el hacker como táctica, el activismo ciudadano y el remix de la conciencia pública. ¡No sonría, está siendo vigilado!

\section{Contexto: optimismo tecnológico, pesimismo ciudadano}

Los estudiosos nos cuentan que habitamos "una nueva experiencia textual" (Scolari, 2013) y una "inteligencia colectiva” (Levy, 2004). La cultura común horizontal, participativa y colaborativa pareciese posible porque "las nuevas tecnologías están permitiendo a los consumidores archivar, comentar, apropiarse de los contenidos mediáticos y volver a ponerlos en circulación”, nos dice Henry Jenkins (2009). Una lucha que se basa en "la creatividad de los fans, las comunidades en línea y la cultura colaborativa" para producir una "fiesta transmedial" e imaginar una "semiótica afectiva" (Jenkins, 2009).

En el horizonte hay amargados como Umberto Eco, que está ofuscado y afirma que

las redes digitales son para los idiotas y para exponer idioteces [porque] las redes sociales le dan derecho de hablar a legiones de idiotas que primero hablaban solo en el bar después de un vaso de vino, sin dañar a la comunidad... y ahora tienen el mismo derecho a hablar que un premio Nobel. Es la invasión de los idiotas. (Eco, 2015)

Eco desconfía de la inteligencia colectiva, y todo porque ha perdido su autoridad intelectual ganada en lo escritural. Y no está solo, el pensador humanista Edgar Morin (2012) afirmó que "los indignados es un movimiento interesante. No son revolucionarios, son rebeldes que representan una contestación, una protesta... [pero] el problema es que carecen de un pensamiento... hacen críticas justas, denuncian pero no pueden enunciar". Otro intelectual que asume que la enunciación política debe ser dada como se construía en la modernidad, que 
eso de tener cabeza y lugar en el mundo para decir cosas con sentido y política solo es posible en las élites del poder académico, político o ideológico. Entonces, según los sabios del siglo XX, en el mundo digital hemos perdido la razón, la cultura y la enunciación política. Aguafiestas que alimentan su desazón de la pérdida de su autoridad cultural.

Entre los que ven un nuevo paraíso y los aguafiestas, como siempre es mejor estar más allá de los dualismos morales. Uno de los luchadores contra los dualismos, Jesús Martín-Barbero, me contó -en perspectiva de Serres (2013)- que la clave está en preguntar de nuevo “¿para qué sirve la cabeza hoy?” Y narra así: antes de la imprenta, la cabeza servía para memorizar y conservar los saberes, los conocimientos y experiencias sociales; con la imprenta, ya el saber se guardó en forma de libro, la cabeza comenzó a organizar y ordenar los conocimientos; con el cine, la cabeza hizo soñar a cada sujeto con ser una estrella en su vida cotidiana; con internet ya no hace falta memorizar, ordenar o soñar, él lo hace por nosotros. Entonces, ¿para qué sirve la cabeza hoy? La cabeza en los mundos digitales sirve para escuchar, mutar e inventar.

\section{Texto: el homo data como mercancía}

Pero ese escuchar, mutar, inventar, en los mundos digitales depende de saberes de programación y gestión de los datos. ¿Qué es la big data? Dicen que es una tecnología revolucionaria. Piscitelli (2015), en su "cátedra de datos", nos cuenta que la definición cuantitativa de la big data tiene nombres extraños como terabytes, petabytes, exabytes, y se pregunta ¿a dónde van los datos cuando nacen? Y la respuesta inocente sería, por supuesto, a un lugar muy provechoso y aprovechable al que llamamos "base de datos".

Es decir, que toda big data se almacena en una base de datos. Una base de datos es una colección de datos organizada. Los elementos que organizan esos datos se llaman metadatos, o también índices [...] El texto de Helen Nissenbaum, "Conocernos mejor que nosotros mismos: bases de datos inmensas y profundas”, nos sugiere revisar el trasfondo de los datos. Nissembaum rescata un primer momento histórico, entre los años 60 y 70 , la era del mainframe, donde las grandes bases de datos computerizadas eran compiladas por el gobierno y las grandes instituciones privadas [...] Luego, la capacidad de procesamiento y almacenamiento en constante crecimiento, inversamente a la caída de los costos de producción de medios de almacenamiento [...] En un tercer momento, la conexión en red vía World Wide Web de esas bases de datos hizo posible la interconexión de datos. El big data es, entonces, un concepto que atraviesa múltiples posibilidades de recolección de datos: los archivos telefónicos, las compras con tarjeta de crédito, los archivos digitales, los cruces de fronteras $y$,

1 Ver Martín-Barbero, 2014. 
por supuesto, la actividad de los usuarios en la World Wide Web, donde, a diferencia del mundo off line, cada una de nuestras actividades deja una traza en una base de datos. El crecimiento del big data dependió entonces de tres factores: capacidad de almacenamiento, capacidad de flujo y capacidad de análisis de datos. Estos tres factores dieron lugar a bases de datos inmensas y profundas, pero una cuarta posibilidad amplió el poder de las bases de datos: la capacidad de agregación de datos, que nos da la posibilidad de recopilar y relacionar varias bases de datos distintas. De esa relación surge un interesante poder de interpretación de datos. Entonces, las bases de datos pueden ser: amplias (muchos sujetos, poca información), profundas (mucha información sobre pocos sujetos), agregadas (combinación de varias bases de datos, amplias o profundas). Una aplicación muy interesante y muy fácil de usar para acercarse a la idea de estos tres tipos de bases de datos es la aplicación GapMinder, creada por Frank Rossling. Ahora habitamos el pasaje de la Big data a la algoritmización de casi todo. No todo algoritmo necesita de big data, pero seguramente la lectura de big data depende de la posibilidad de inventar algoritmos para leerlos [...] Un algoritmo es un conjunto general de instrucciones codificables y un conjunto ordenado y finito de pasos que nos permite solucionar un problema. [...] Y todo es más codificable de lo que pensamos. (Piscitelli, 2015)

Según Mayer-Schönberger y Cukier (2013), el giro del Big Data es "la revolución de los datos masivos", que se caracteriza teóricamente como una sociedad que pasa de la causalidad de la información a la correlación de datos, un pasar del Newton que busca causas a la correlación de futuros, de la ignorancia a la datificación de los hábitos y costumbres, las epidemias, los consumos, la vida de la gente. Con el Big data la causalidad pierde terreno a favor de la correlación. No sabemos por qué, pero nos damos cuenta de que cuando sucede una cosa muy probablemente sucede otra. La nueva mentalidad pasa por aceptar el desorden y la imprecisión del mundo, sin embargo, con base en algoritmos suele ser más predictiva. Mientras que la causalidad nos ayudaba a entender lo que sucedió en el pasado, la correlación nos lleva a poder, en gran medida, predecir el futuro. Habitamos otro tiempo (el futuro leído en clave de pasado) y otro espacio (lo digital como territorio), y todo es posible por la correlación de datos disponibles.

Dejando la discusión técnica y teórica, bajemos a la cancha. Ahí descubrimos que el juego, o lucha, indica que el mundo digital es donde Google sabe más de nosotros mismos que uno mismo -como dijo Jesús Martín-Barbero-y donde Youtube construye nuestra imagen pública; un mundo en que, siguiendo nuestros consumos culturales (big data), Amazon establece la secuencia de lo próximo que querremos leer o consumir y Netflix nos aconseja lo que debemos ver; uno donde Facebook reinventa la amistad y Twitter el periodismo, la farándula y la opinión pública. San Steve Jobs es el genio del neg-ocio que puso de moda el touch como actitud, la tableta como pantalla y consumir por 0,99 dólares. La censura ya no es posible porque todo se vende y todo se compra en red. Y, en el mundo de los medios, la moda es el periodismo de datos. Y en los 
mundos académicos gana la ciencia de datos. Y en la democratización del saber habitamos la investigación colectiva de datos. Los datos mueven el mundo y lo hacen para bien. Pero,

"nos basamos en metadatos para matar gente" declaró el director de la CIA y la NSA, Michael Hayden. Ya no hay parcela de la vida ni de la muerte que no esté regida por el Big Data, esas monstruosas masas de información que las empresas y los gobiernos nos tratan de procesar para que arrojen luz, sentido. La información que diseminamos mediante nuestros teclados y los sensores de nuestros teléfonos móviles se crea pero no se destruye: transformada, traducida, viaja por cables de fibra óptica y es almacenada en tanques faraónicos, viveros de datos, archivos en polígonos industriales como los que se ven al final de la tercera temporada de Person of interest, la única serie norteamericana que está abordando, mediante mercenarios, hackers y corporaciones de la videovigilancia, nuestra distopía cotidiana. (Carrión, 2014)

La censura, la vigilancia y el control existen, pero lo que es peor: no nos damos cuenta. Hay vigilancia masiva, hay control de intimidades y disidencias. Y se hacen vía Netflix y Amazon, Facebook y Google, Wallmart y los gobiernos. Las empresas y los gobiernos han abrazado "la religión de los datos" con el objetivo de extraer rendimiento económico y político a toda esta información. La orientación a los datos es la nueva forma de centrarse en el cliente (negocio) y vigilar terroristas (ideología). "Los datos son el petróleo del siglo XXI, un nuevo factor de producción que se une a la tierra, el trabajo y el capital”, afirma Jorge Carrión (2015).

El verdadero salto cualitativo se juega en el terreno del poder: el que sea capaz de innovar dando sentido y monetizando este banco enorme de hechos ganará la partida. Cada usuario de Facebook puede valorarse en unos 100 euros. Cada tuit, a la hora de ser analizado, incluye 33 parámetros diferentes que permiten extraerle rendimiento. En último término, la vida, la experiencia y el tiempo humano es el que se convierte en una "commodity" (Mayer-Schönberger \& Cukier, 2013). El poder y el control de empresarios y gobiernos existen porque son los que hacen hablar a los datos, a las máquinas, a los algoritmos. El riesgo para la democracia es más que evidente. Y por eso es que Carrion (2014) logra un afortunado tuit: "En los últimos años hemos cambiado el Big Brother por el Big Data". Y los riesgos del Big Data son la falta de intimidad o el robo de datos, pero sobre todo creer que los datos nunca mienten y que ya no hay ideología o moral, sino predicción objetiva determinista por la tecnología -como que se puede predecir quién puede ser asesino o terrorista por los datos que ha venido usando (Mayer-Schönberger \& Cukier, 2013).

Para el caso, basta con mirar a las agencias de seguridad del estado colombiano, que han invertido muchos millones en comprar software espía a empresas italianas e israelíes para interceptar a sus ciudadanos en busca de guerrilleros. La fiscalía tiene un sistema llamado "Esperanza" (como todo poder 
de control es cínico, se le llama "esperanza" a lo que atenta contra la democracia), la policía tiene "Galileo" (otro cinismo más) y está desarrollando ahora uno propio llamado "Puma" (Plataforma Única de Monitoreo y Análisis). Además de los correos electrónicos, con estos se pueden escuchar y grabar llamadas de Skype y todos los movimientos de la gente en WhatsApp, Viber, Hangouts. Activar los micrófonos, rastrear las contraseñas y detectar la ubicación del teléfono. Se puede todo, menos la democracia, la libertad y la protección del ciudadano.

El 13 de noviembre de 2015 ocurrió la masacre de París. Parecía un videojuego. ${ }^{2}$ Esta masacre de París fue contada primero en las redes y luego en los medios. En Periscope (donde todos devenimos periodistas) se oyeron los disparos en vivo, en Facebook (donde todos somos comunidad) los rehenes pidieron auxilio y en Twitter (donde la autorregulación o catarsis emocional es la verdad) se jugaron la noticia y la bronca. Todo esto llevó a que la masacre de París fuera una tragedia registrada en digital. París - Attack - Bataclan ENTER. Tras teclear estas palabras en Google aparecen 8 millones de resultados en vídeo. En Facebook, el mensaje de la banda "Eagles of Death Metal" sobre la masacre durante su concierto en el teatro Le Bataclan fue compartida 38 mil veces y tuvo más de 165 mil "me gusta"; en Twitter fueron tendencia \#ParisAttacks \#ISIS \#Parisi3N y \#JeSuisParis. Twitter se convirtió en un muro de indignación y dolor. Todos con Francia, todos contra el terrorismo. Twitter dejó que sus usuarios se autorregularan. Los xenófobos y los no xenófobos, los indignados, los parisinos, los musulmanes. Todos hablando de lo que quisieran, como quisieran.

En Facebook lo que pasó fue diferente. Esa misma noche, Facebook decidió activar su aplicación "safety check" para que sus usuarios dijeran que estaban vivos con un clic. Una función que, según Zuckerberg, antes solo era usada para desastres naturales pero que, ante lo ocurrido, la empresa decidió cambiar su política. Así muchos, y de manera muy eficiente y limpia, supieron si sus conocidos y significantes estaban vivos y a salvo. Gran servicio. Eficiencia higiénica, Facebook. El 14, de noviembre Zuckerberg cambió su foto de perfil en Facebook cubriendo su cara con un filtro de la bandera de Francia. Su foto fue vista por los 41 millones de personas del mundo que lo siguen en su red. Como si toda Colombia siguiera a este dios digital. Y la bandera filtro cubrió la cara de muchos, millones de usuarios de Facebook. La gente se hacía parte de la tragedia o de su conciencia con la bandera encima de su rostro. Y surgió la pregunta ¿cuál es el papel de la red más popular del mundo en la que hay 1500 millones de usuarios? Y hubo respuestas: un nuevo espacio para la democracia y la opinión pública; pero una democracia y opinión localizadas que permiten tener solidaridades y opiniones de gueto. Frédéric Martel en Smart (2014) afirma que no hay un internet sino "los internets", porque cada comunidad es una "localización":

2 Las referencias al uso de la masacre de París por parte de Facebook es una reflexión que se construye con el aporte de la profesora María Paula Martínez, del Centro de Estudios en Periodismo de la Universidad de los Andes. 
puede ser que los sujetos estén por todo el mundo pero conforman una comunidad cercana. Y el asunto político: somos datos. Datos puestos, cliqueados, likeados, comentados. Facebook y las redes digitales han olvidado el lado humano de la vida: las víctimas, los victimarios y el nosotros.

Para comprender los diversos matices de la cultura del control a partir de datos es muy útil revisar la revista Teknokultura (2015), que trata acerca del problema de la vigilancia tecnológica por parte de gobiernos y corporaciones y sus implicaciones políticas y democráticas. Se aborda el derecho a mirar en los tiempos de los drones y los modos de vigilancia digital en Ecuador, Venezuela y Colombia. La misma revista documenta que, así como surgen iniciativas que vulneran el derecho a la privacidad, aparecen proyectos ciudadanos que salen en su defensa, reclamando que se la considere un derecho humano, al mismo nivel que la libertad de expresión (como es la experiencia de las movilizaciones por la defensa de los derechos digitales en Brasil). En este contexto, es en el que afirmo que la big data es la cancha donde se está jugando la democracia.

\section{Divergencia: el internet de las cosas}

En ese espacio ambiguo que son los mundos digitales (internet, redes, celulares, aplicaciones, programas), más allá de los aguafiestas o los convencidos, está todo: habitamos un nuevo territorio sin tiempo ni espacio. Ya no importa el lugar ni la duración, todo es experiencia. Y en esa experiencia digital hay una guerra de los datos: una batalla entre libertad y control, entre placeres y negocios, entre intimidades y mercado. El evangelio de "los vendedores de humo digital" (comerciantes, académicos, geeks, fans, políticos) profesa una fe ciega en la religión de internet, las redes digitales, las aplicaciones y los datos... y predica que ahora sí todo es posible, mejor, más innovador y más democrático: hasta la pobreza y las drogas y las violencias se resuelven con una tableta y un plan de datos (eso dijo el ministro de TIC en Colombia). Pero, como toda fe, tiene su ambigüedad, y hay quienes hacen de esta fe una ideología y quieren preservar lo digital de "pecado" (comerciantes, académicos, moralistas, políticos) en nombre de valores superiores (familia, religión, gobierno), quieren controlar la libertad en la red y buscan el control por la ley o la fuerza; estos predican que una tableta o un celular más que una liberación es una perversión para los niños, la familia, la religión y el proyecto político; ante la maldición de la pornografía y el terrorismo, y por la salud moral de la sociedad, todo debe ser vigilado y controlado. La paradoja está en que geeks de "todo es posible" y moralistas de "todo debe controlarse" están de acuerdo en que el asunto es un problema de leyes y educación: los geeks apuestan por hacer de las prácticas y procesos de aprendizaje experiencias de libertad creativa, mientras los moralistas afirman que se debe “alfabetizar" a los niños y establecer normas legales y morales de control. 
Mientras andamos en esas discusiones inútiles, los mundos digitales avanzan y lo hacen de manera seductora. Uno de sus inventos más maravillosos se llama "el internet de las cosas". Este es un concepto que se refiere a la interconexión digital de objetos cotidianos con Internet o cuando las "cosas u objetos" se conectan a Internet para convertirse en información (data) útil. El concepto de "internet de las cosas" fue propuesto por Kevin Ashton en el Auto-ID Center del MIT en 1999. Cada cosa, aparato o máquina debería funcionar conectado a internet para saber su existencia, ubicación, precio y cualidad: el control total de objetos y personas mediante datos. O sea, Internet se encargaría de gestionar la vida de las cosas y los humanos. Las máquinas gestionan datos para nuestro servicio y/o control. Y cuenta Wikipedia que "la empresa estadounidense Cisco ha creado un 'contador de conexiones' dinámico que le permite estimar el número de 'cosas' conectadas desde julio de 2013 hasta el 2020”. Esto del internet de las cosas es una guerra entre la máquina (control) y el hombre (libertad): la guerra de los datos.

Así que internet es, en realidad, un dispositivo acerca de cómo gestionar al ser humano llamado individuo/cosa en el mercado de los datos. La principal "cosa" que gestiona internet es el ser humano. De él o ella sabe quién es, cómo vive, qué sueña-compra-desea. Internet se encarga de gestionar la libertad de "esa cosa" llamada "humano". Y cada vez mejor: tu Iphone o teléfono inteligente compra y decide por vos: la única garantía, tu huella digital.

Los humanos somos la cosa, el dato y el deseo más "identificado", "relacionado" y "gestionado" por internet, el celular y las aplicaciones. Él sabe todo de nosotros: nuestros gustos, nuestros consumos, nuestras virtudes, nuestros deseos: sabe más de uno mismo que uno mismo. Nos siguen el rastro: Amazon sabe qué libros nos gustan, Netflix qué películas y series preferimos, Google qué páginas visitamos, Youtube nos selecciona los vídeos y construye nuestra imagen pública, en Twitter jugamos a tener opinión única, en el selfie intentamos cosificar nuestros momentos y a Facebook le regalamos nuestros deseos íntimos. El "internet de las cosas" consiste en vigilar, controlar y administrar la cosa mayor, que es el ser humano.

A partir del uso de la big data, las empresas de tecnología, las empresas del capitalylosgobiernos se adueñan denuestros tiempos, deseosylibertades:toman posesión de nuestros ocios, nos definen lo que es libertad y entretenimiento, invaden nuestros momentos productivos y de deseo. El tiempo es una cosa que nos gestiona internet: el tiempo ya no nos pertenece, es de internet. Y el espacio ya no existe, habitamos la geo-referenciación de la web: ella nos sigue, nos dice dónde estamos y qué hay ahí. Es más, ya existe Tinder, que me dice si en ese espacio-tiempo que habita nuestro wifi o celular hay alguien disponible para el sexo casual o compartir su soledad. Tener tecnologías es estar más conectado: y estar conectado es ser más súbdito de los gestores de datos. El sexo, los amigos, los gustos, los deseos son cosas que nos gestiona internet: somos humanos sujetados a los datos digitales: somos su gran cosa. La paradoja es que somos 
felices siendo "cosas" porque somos públicos, tenemos visibilidad, existimos en las redes, nos creemos estrellas de nuestra vida y protagonistas de la farándula social. La cosa humana está disponible para ser administrada por internet: eso es la felicidad del siglo XXI.

En la educación, el "internet de las cosas" que trabaja sobre el big data es una maravilla. Permite establecer relaciones entre conceptos, procesos, maestros, prácticas, saberes y contextos culturales. Imaginemos que tenemos un concepto que enseñar-aprender-comprender-explicar: pongamos que sea "democracia", uno de los más abstractos y potentes para la vida moderna y la experiencia, que está en peligro en tiempos de la big data. Internet relaciona "democracia" con la vida del estudiante, con sus gustos, sus deseos, sus links y secuencias, su contexto cultural, sus otras asignaturas, sus rituales afectivos, sus prácticas educativas y lúdicas, sus consumos y deseos. Entonces todo se conecta y aparecen los vacíos, pero también las potencias, y de esta forma el concepto cobra sentido para la vida cotidiana y para la vida social y digital del estudiante. Y así podría ser con cada uno de los saberes básicos desde las ciencias sociales, las artes y los deportes, hasta las matemáticas y las ciencias duras. Alucinante porque lo digital hace bien lo que la educación hace mal: la producción de relaciones, contextos y sentidos (no es saber ni memorizar, es articular, relacionar, localizar los saberes lo que hace que la educación tenga sentido).

El internet de las cosas y la big data son una maravilla educativa porque (idealmente) nos permiten pasar de los saberes fragmento (un estudiante y sus redes: individualismo capitalista) a los saberes conexión de pantallas, links, conceptos, contextos, saberes y prácticas (un concepto y sus redes: capitalismo solidario). Así podríamos tener una experiencia educativa, en cuanto se experimenta la gestión de un sistema de relaciones, conexiones y contextos. Por eso, más que meter en el aula el Facebook o la tableta, hay que meter todo el ecosistema de pantallas y aplicaciones y redes para que el proceso de aprender-saber se convierta en una narración extendida, una red de conexiones y contextos: educarse será producir sentidos y no repetir de memoria o esa cultura del "corta-pega".

Este es el ideal y la posibilidad, pero la experiencia cotidiana que se da es al revés: el big data gestiona al ser humano como cosa, para hacer de esa cosa llamada humano (estudiante, trabajador, joven, ama de casa) un gran negocio y un súbdito sin libertad.

\section{Post-texto: activistas digitales por bronca y diversión}

Todo esto parece muy lejano del ciudadano, que sigue dando sus datos e informaciones inocentemente. El gobierno Uribe en Colombia hizo seguimiento a sus opositores, los jueces y los periodistas en un caso llamado "las chuzadas" (interceptación ilegal de correos electrónicos, documentos en web y llamadas 
telefónicas de cerca de 600 personas), ${ }^{3}$ ya hay en la cárcel varios de sus colaboradores pero, sin embargo, el expresidente sigue afirmando que eso es "una bobadita". Murdoch y su diario News of the world fueron obligados a pagar indemnizaciones, cerrar el periódico e ir a la justicia por seguir a políticos y celebridades en Inglaterra. Un caso banal, cuando cumplí 50 años, al día siguiente me comenzaron a llegar miles de correos electrónicos ofreciéndome Viagra. A las mujeres embarazadas les comienza a llegar información de bebés. Al consumidor de Amazon le indican libros, y así nos siguen nuestros comportamientos para indicarnos cómo debemos comportarnos o a qué debemos temer. El big data sirve para intimidar a la oposición política, para detectar terroristas, para hacer limpieza de militantes, para ganar escándalos mediáticos, para ganar consumidores y hacer buenos negocios. Estamos en sus manos y no podemos seguir sonriendo inocentemente. ¿Qué podemos hacer los ciudadanos?

Comprender que la transparencia tecnológica no existe: que hay ideologías y políticas en las aplicaciones, programas, plataformas y empresas de lo digital. Y recuperar la idea de red humana más allá de lo digital: pasar de la red tecnológica de usuarios al territorio ciudadano y político de la calle. También hay que comprender que las redes digitales son como enjambres de abejas para picar, politizar y divertirse en simultáneo: "instantes" colectivos para una nueva política con ejemplos fascinantes como "la primavera árabe" (Túnez, Egipto, Libia, Siria...), Occupy (NY), 15M (Madrid), \#YoSoy132 (México), "me pongo la ruana” (Colombia), \#leyPulpin (contra la ley para un nuevo régimen laboral juvenil en Perú), “redesfrenteamplistas” (Uruguay), Media Ninja (Brasil), Movimiento estudiantil (Chile), "Junho: das ruas e das redes" (Brasil). Pero que las redes digitales pican e hinchan pero no son el movimiento ni toda la política.

Asumir que, aunque cada vez parece más difícil decir que las redes digitales son un lugar "democrático" (porque estas solo tienen de social que agregan gentes-datos-links-cuentas, ya que no crean sociedad entre diversos sino que excluyen a los no conectados y a los que no piensan igual, juegan en jerarquías de poder y mercado y no son libres, sino que están siendo controladas y vigiladas), son la democracia porque son el terreno donde se juegan las políticas de los datos y, por tanto, se juegan las ciudadanías, los derechos, las libertades. Aunque el pesimismo nos habite, no hay otra posibilidad que la de "activarnos" como ciudadanos y "politizar" las redes digitales para existir como "nuevos sujetos políticos" de la democracia.

Polinitizar en las redes digitales y polinitizar en la sociedad: hay que picar más y juntarse más: polinizar en la red y politizar en la calle. Por eso se propone que, para entender la política en las redes digitales, las aplicaciones y los aparatos celulares hay que ir a la metáfora de las abejas. Su función en el mundo es ir "polinizando" de flor en flor. Es decir, mezclando, picando y chupando,

3 Este dato está en un informe sobre vigilancia en Colombia: "How Colombia built a shadow state, a new Privacy International investigation reveals", disponible en: https://www.privacyinternational.org/node/636. 
que las abejas encantan, emocionan y enriquecen el ecosistema: en cada flor van dejando lo de otras y así construyen un ecosistema vital y potente. Hoy las abejas están desapareciendo porque pican y hacen daño (y, por lo tanto, se las evita) y porque en cada flor se envenenan de tantos químicos que se ponen a las plantas (el sistema del mercado y la política está lleno de venenos) que no polinizan: se envenenan y mueren. $\mathrm{Y}$ el ecosistema muere (la democracia muere). Recuperemos la política en las redes digitales, su acción de "polinizar" (picar, mezclar, emocionar, conectar) como manera de politizar. Este acto de polinizar lleva a que la sociedad se "politice" (interrelacione, se interese, se colectivice, se emocione) pero luego debe estar el movimiento y el partido político, y la calle y la intervención en las instituciones del territorio de lo político. Poliniticemos picando al sistema con anarquismo y derechos humanos, con bronca y conciencia, no nos dejemos joder el sistema, intervengámoslo. Para dejar de ser data y convertirnos en ciudadanos, activistas y militantes de esa otra sociedad que exigimos.

En este contexto, hacer política en la red es como polinizar en el mundo de las abejas, politizar a cada sujeto-red para que transforme el sistema. Por ahora se poliniza/politiza muy poco porque su accionar duele (y los políticos y su sistema institucional nos evitan) y nuestro mezclar y juntar en misiones está envenenado y nos lleva a la frustración, el desencanto y la huida en el consumo (para qué activar si siempre nos envenenan de burocracia, cinismo y corrupción).

En la oscuridad tecnológica de las TIC, las manadas se juntan y activan. Hay ejemplos de otra polinitización: uno, el Tejido de Comunicación de la Asociación de Cabildos Indígenas del norte del Cauca-ACIN (http://www.nasaacin.org/) que afirma que lo que hacen es "caminar la palabra" y "tejer con palabras y experiencias”; por lo tanto, no es solo crear redes, sino tejer con colectivos dentro del territorio que usan los medios y las estrategias para hacer vibrar la red. Todo esto se hace y construye como proyecto político con un uso intensivo de las redes digitales. En otra lógica, una que nace de las músicas y las culturas populares, emerge Fora do Eixo en Brasil (http://foradoeixo.org.br/) para producir una organización político-cultural de base popular que, desde y en el espacio digital y habitando el territorio, disputa las narrativas mediáticas y las formas clásicas de hacer política; los miembros de la red viven en casas colectivas, donde comparten en la vida real sus vidas: una vida más allá de la red. En estos dos casos, el tejer comunidad no es un invento de lo digital sino que se construye en el territorio y en lo digital, eso politiza desde el tejer-con-otros y la producción del colectivo. Y hay más acciones de polinización y picar desde y en la redes como testimonia "Jóvenes y poliTICs en América Latina" (http://bit.ly/2aDwNXT).

Las formas de hacer política en el siglo XXI ya juegan a lo digital. Los partidos y las viejas organizaciones como el sindicalismo ya no funcionan en los viejos modos, porque, aunque se han digitalizado, no convocan, ni seducen. En todo caso, pueden volver a convocar y activar ya que los campesinos ahora cosechan con smartphone, los sindicalistas tienen grupos de WhatsApp, los estudiantes 
viven en Youtube, los presidentes en Twitter... Tal vez falta entender que no basta con tener aparatos, sino que deben poner en escena su saber activista, sus modos de resistir/inventar, sus solidaridades y activismos de calle.

De los viejos medios poco se puede esperar porque se han convertido en actores políticos, defensores de la sociedad de mercado y la ganancia cínica, y han dejado de jugar por la calidad informativa y del entretenimiento.

Los ciudadanos debemos tomar conciencia sobre este big problema de intimidad y democracia. Debemos abandonar la inocencia del cliquear "Me gusta", el "estar conectado" y "el placer de exponerse". No basta con querer pasárselo bien con amigos y evitar la solemnidad, sino que hay que ganar la política, el activismo, la posibilidad de actuar colectivamente para protegernos (Haaf, 2012). Hay que asumir que habitamos una mutación, que el mar que navegamos ya no es el mismo, que hay un nuevo aire de tiempo y que la democracia ya no volverá a ser lo que era.

También debemos recuperar el "capital cultural pop" del mundo digital como referente común de sentido, experiencia y acción y su potencia contracultural contra la vigilancia, el mercado y el control; en el movimiento estudiantil chileno, por ejemplo, fue más político bailar Thriller de Michael Jackson que cantar juntos "el pueblo unido jamás será vencido" (lo cual es, además, una mentira: al pueblo siempre lo vencen).

Un atisbo de optimismo surge porque los jóvenes andan en bronca con este mundo, con los modos cínicos del capital, los medios, los partidos, los sindicatos y la democracia. Y esa bronca es su modo de hacer política: esa rabia se puede convertir en un grito digital para, desde ahí, politizar a otros. Pinchar en la red es politizar para los habitantes de lo digital.

En este contexto, hacer política en la red es como polinizar en el mundo de las abejas, politizar a cada sujeto-red para que transforme el sistema y habite el territorio. Debemos convertirnos en activistas, hackers y defensores del código abierto para, desde la rabia, la crítica, la joda y el entretenimiento, crear nuevas maneras de estar juntos. Debemos buscar hacer posible la creación colectiva y el anarquismo que se ocupa de lo que indigna. Habitar el hackear, el samplear, el dj, el jammer, el mixturar. Reconstruir, transformar, jugar (ver Everything is remix). Buscar la comunidad descentrada, horizontal auto-organizada y co-productiva. Pasar del viewer (solo ve) y del user (ve y usa) al player (ve, usa y juega) y al maker (hacedor). Frente al big data ejercer el saber "videojuego" para contar y activar historias en la dimensión del interfaz. "Somos mutantes, mamá", dice Lucas. Ante el big data ejerzamos de mutantes y anarquistas, y virusiemos al sistema. 


\section{Referencias bibliográficas}

Carrión, J. (2014). Mundo de datos. Barcelona: exposición Big Bang Data en CCCB.

Carrión, J. (2015). Periodismo expandido. Bogotá: Curso de Maestría en Periodismo, Universidad de los Andes, junio 22 al 26.

Eco, U. (2015). Las redes sociales le dan espacio a los idiotas. El Comercio-GDA, 17 de junio de 2015 .

Haaf, M. (2012). ¡Dejad de lloriquear! Sobre una generación y sus problemas superfluos. Madrid: AlphaDecay.

Jenkins, H. (2009). Fans, blogueros y videojuegos. Barcelona: Paidós.

Fescomunicacion. (2014). Jóvenes y poliTICs en América Latina. En http://bit. ly/2aDwNXT.

Levy, P. (2004). Cibercultura. Barcelona: Antropos.

Martel, F. (2014). Smart. Internet(s): Una investigación. Barcelona: Taurus.

Martín-Barbero, J. (2014). Manifiestos: incómodos, desobedientes, mutantes. Bogotá: FesComunicación. Disponible en http://bit.ly/1JgNOAv.

Mayer-Schönberger, V. \& Cukier, K. (2013). Big data. La revolución de los datos masivos. Madrid: Turner.

Morin, E. (2012, 13 de marzo). Los indignados denuncian; no pueden enunciar. El País. España.

Piscitelli, A. (2015). De la big data a la algoritmización de ¿todo?. Cátedra de datos, Teórico $\mathrm{n}^{\circ}$ 4. Disponible en: http://bit.ly/1L4.WywE.

Revista Teknokultura (2015) Vol. 12, N. 3, diciembre del 2015. Universidad Complutense de Madrid. Disponible en http://revistas.ucm.es/index.php/TEKN/ issue/view/2905/showToc

Scolari, C. (2013). Narrativa Transmedia: cuando todos los medios cuentan. Barcelona: Deusto S.A ediciones.

Serres, M. (2013). Pulgarcita. México: Fondo de Cultura Económica. 